\title{
Can mosses serve as model organisms for forest research?
}

\author{
Stefanie J. Müller • Desirée D. Gütle • \\ Jean-Pierre Jacquot • Ralf Reski
}

Received: 30 October 2014 / Accepted: 23 February 2015 / Published online: 17 March 2015

(C) INRA and Springer-Verlag France 2015

\begin{abstract}
- Key message Based on their impact on many ecosystems, we review the relevance of mosses in research regarding stress tolerance, metabolism, and cell biology. We introduce the potential use of mosses as complementary model systems in molecular forest research, with an emphasis on the most developed model moss Physcomitrella patens.

- Context and aims Mosses are important components of several ecosystems. The moss $P$. patens is a well-established nonvascular model plant with a high amenability to molecular
\end{abstract}

Handling Editor: Jean-Michel Leban

Contribution of the co-authors S.J.M. and D.D.G. wrote the manuscript under the supervision of J.P.J. and R.R.

S. J. Müller $\cdot$ D. D. Gütle $\cdot$ R. Reski $(\bowtie)$

Plant Biotechnology, Faculty of Biology, University of Freiburg,

Schaenzlestr.1, 79104 Freiburg, Germany

e-mail: ralf.reski@biologie.uni-freiburg.de

D. D. Gütle $\cdot$ R. Reski

Spemann Graduate School of Biology and Medicine (SGBM),

University of Freiburg, Albertstr. 19A, 79104 Freiburg, Germany

D. D. Gütle · J.-P. Jacquot

Interactions Arbres-Microorganismes, UMR1136, Université de Lorraine, 54500 Vandoeuvre-lès-Nancy, France

J.-P. Jacquot

Interactions Arbres-Microorganismes, UMR1136, INRA,

54280 Champenoux, France

R. Reski

BIOSS Centre for Biological Signalling Studies, Schaenzlestr. 18, 79104 Freiburg, Germany

R. Reski

FRIAS Freiburg Institute for Advanced Studies, Albertstr. 19,

79104 Freiburg, Germany

R. Reski

USIAS Strasbourg Institute for Advanced Study, Strasbourg, France biology techniques and was designated as a JGI plant flagship genome. In this review, we will provide an introduction to moss research and highlight the characteristics of $P$. patens and other mosses as a potential complementary model system for forest research.

- Methods Starting with an introduction into general moss biology, we summarize the knowledge about moss physiology and differences to seed plants. We provide an overview of the current research areas utilizing mosses, pinpointing potential links to tree biology. To complement literature review, we discuss moss advantages and available resources regarding molecular biology techniques.

- Results and conclusion During the last decade, many fundamental processes and cell mechanisms have been studied in mosses and seed plants, increasing our knowledge of plant evolution. Additionally, moss-specific mechanisms of stress tolerance are under investigation to understand their resilience in ecosystems. Thus, using the advantages of model mosses such as $P$. patens is of high interest for various research approaches, including stress tolerance, organelle biology, cell polarity, and secondary metabolism.

Keywords Physcomitrella patens · Model plant · Gene targeting $\cdot$ Abiotic stress $\cdot$ Evo-devo $\cdot$ Cell biology

\section{Introduction}

Often, the ability to disproof or to support a scientific hypothesis in an experiment depends on the choice of the biological model system. In life sciences, several model species have been used in relation with the different advantages they offer in terms of generation time, growth, evolutionary position, or amenability to molecular biology techniques (Jansson and Douglas 2007; Müller and Grossniklaus 2010; Reski 1998). 
In plant sciences, several seed plant model species are established, whereas lycophytes and ferns are more problematic model organisms due to their low transformability or large genome size (Plackett et al. 2014). Liverworts, mosses, and hornworts constitute the paraphyletic group of bryophytes and represent early diverging lineages of land plants with an intermediate position between vascular plants and algae (Kenrick and Crane 1997; Lang et al. 2010). Many moss features are regarded as ancestral, though their special life style has led to the evolution of many moss-specific morphological and physiological traits, which support alternative survival strategies among land plants (Mishler and Oliver 2009). While the simple morphological structure of mosses is largely conserved since at least 330 million years (Hubers and Kerp 2012), they colonize an extensive spectrum of diverse habitats (Turetsky 2003; Turetsky et al. 2012). Their occurrence in many extreme habitats such as the Antarctic tundra and deserts implies the existence of many yet unknown moss-specific survival mechanisms (Oliver et al. 2005; Roads et al. 2014). The resilience of mosses could recently be demonstrated with the successful regeneration of subglacial bryophytes following 400 years of ice entombment (Farge et al. 2013) and even by the regrowth of over 1500-year-old moss from the Antarctic permafrost (Roads et al. 2014).

However, besides these extreme examples, mosses are also important components of tropical systems (Gradstein et al. 2001), boreal forests, and woodlands or unshaded habitats in temperate zones (Turetsky 2003). Despite their small size, mosses have a huge impact on various ecosystems and are essential contributors to complex biological cycles. Besides the prevention of soil erosion, the development of microtopography, and the regulation of soil climate and water availability, main aspects are nitrogen fixation and carbon cycling.

For instance, mosses are important contributors to bog formation and carbon trapping (Jones et al. 1994; Shaw et al. 2003 ) in peat lands, where almost $100 \%$ of the ground layer is covered by mosses (Vitt and Wieder 2009) such as Sphagnum species. The relevance of biotechnology approaches regarding the production and cultivation of peat mosses is increasing due to the rising demand of peat as, e.g., substrate for horticulture (Beike et al. 2015a).

In forest ecosystems such as rain forests, in which mosses live in immediate vicinity to vascular plants, they can serve as water reservoir (Gradstein et al. 2001) as well as bio-indicators for environmental changes and air pollution (Bates 2009).

The role of mosses for nitrogen fixation in boreal forests is a research area of high interest, as a substantial amount of nitrogen fixation can rely on feather moss-cyanobacteria associations (DeLuca et al. 2002; Rousk et al. 2013).

Hence, mosses represent an omnipresent organism group whose impact is seldom taken into account in forest research and which deserve attention as attractive model systems regarding ecology as well as regarding fundamental processes and evolution of land plants. Moss model species include, e.g., the Funariaceae Funaria hygrometrica and Physcomitrella patens, the Ditrichacea Ceratodon purpureus, and peat moss (Sphagnum) species. Moreover, some model mosses provide extensive advantages for research projects employing molecular biology. The currently most developed model moss is $P$. patens, a moss of the temperate zones which can be found on soil exposed by falling water levels or on fields (Cove 2005). It provides a fully sequenced genome (Rensing et al. 2008), many resources for -omics techniques, a high amenability to microscopy, and a valuable experimental platform for comparative studies with other model organisms, as, e.g., trees. Therefore, the Physcomitrella genome was designated, like poplar, as a "JGI plant flagship genome" (http://jgi.doe.gov/ourscience/science-programs/plant-genomics/plant-flagshipgenomes/). Potential research areas include general moss physiology, moss-specific stress resistance mechanisms, putatively interesting for the transfer to seed plants, as well as research on fundamental mechanisms which evolved early and are conserved in many land plants. In addition, the technical advantages of the moss system can offer complementing approaches to many open questions in seed plant research by, e.g., enabling the manipulation of the genome down to the single base pair level by homologous recombination.

This review gives a basic introduction into moss biology and the current reference model Physcomitrella and its advantages, and provides an overview of the current use of mosses to gain knowledge in different research areas, with an emphasis on potential links with molecular tree research.

\section{The moss model: particularities and advantages}

Plants started to colonize the land mass of Earth about 450 500 million years ago (Kenrick and Crane 1997; Lang et al. 2010), shaping the new environment and establishing the basis of land ecosystems, paving the way for the colonization by animals. During land plant evolution, many adaptations occurred, some of them leading to large radiation of new groups, as, e.g., the flowering plants. Ancestral features of land plants can be either reconstructed from fossils or by the investigation of early diverging land plant groups, as mosses. Though for some aspects moss biology is similar, in others it is fundamentally different from flowering plants.

\subsection{Mosses are haploid dominant}

All plants undergo an alternation of generations between a diploid sporophyte and a haploid gametophyte. Whereas in all vascular plants the sporophyte is the dominant generation, in bryophytes the gametophyte forms the main photosynthetically active plant body (see Fig. 1). Hence, in a 


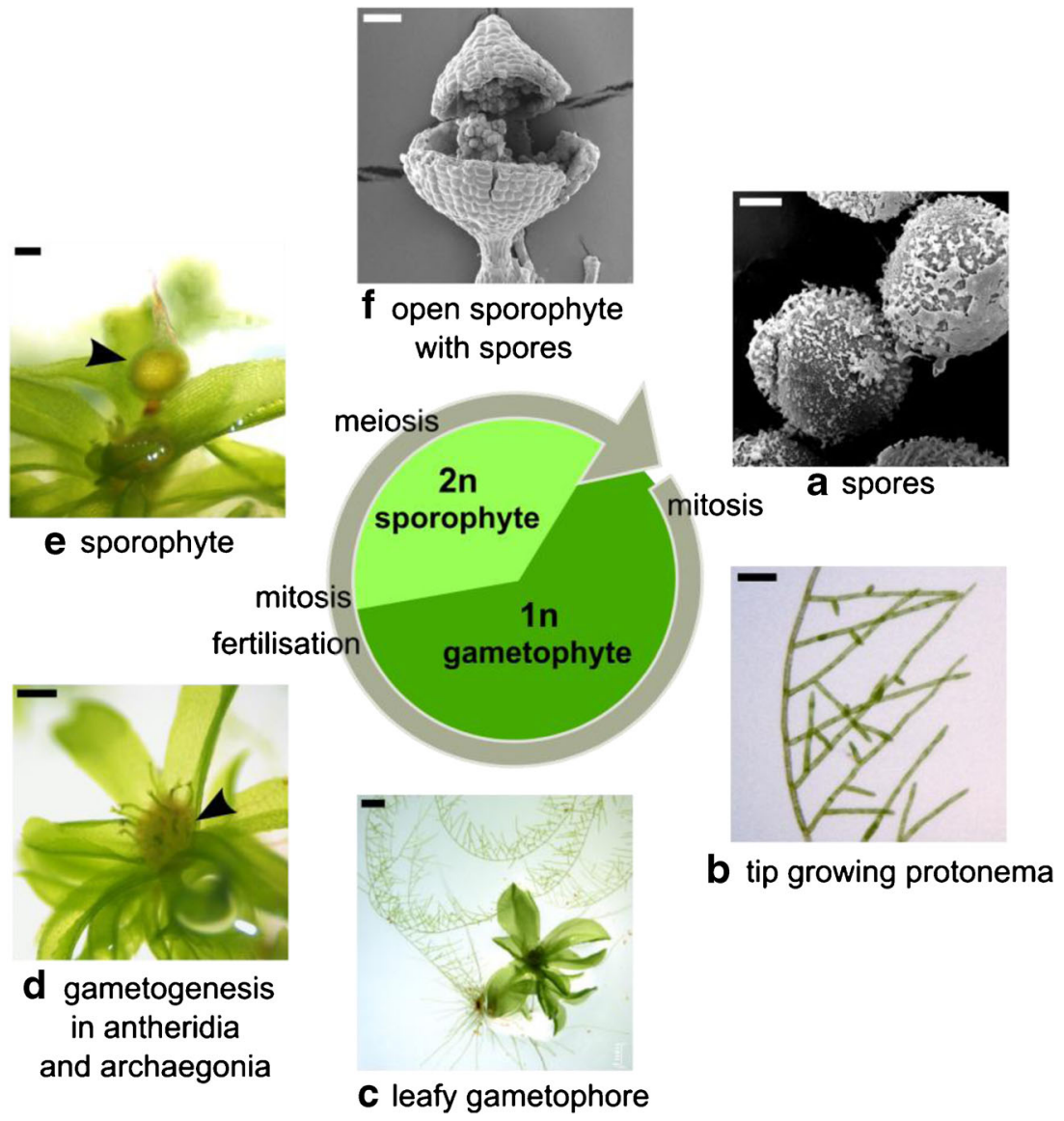

Fig. 1 The life cycle of Physcomitrella patens. Development in Physcomitrella patens starts from the haploid spore, which forms protonema, a tip growing filamentous tissue. During the juvenile-toadult transition of the moss gametophyte, the protonema forms buds which contain a three-faced apical meristematic cell (Harrison et al. 2009) able to generate the leafy gametophore. Within several weeks of inducing conditions $\left(15^{\circ} \mathrm{C}\right.$ short day), male and female sexual organs

developmental comparison of homologous structures between non-vascular and vascular plants, moss gametophytes correspond to flowering plant gametophytes, i.e., the pollen and the embryo sac. At the molecular level, the developmental programs underlying the gametophyte and sporophyte body plans are often not synapomorphies of land plants and rely on different mechanisms (Sakakibara et al. 2013).

Though mosses are haploid during a large fraction of their life, i.e., possess just one allele of each gene, they can often cope with higher amounts of toxic or mutagenic substances compared to flowering plants (Charlot et al. 2014; Harrison et al. 2009). Considering the absence of a second allele which could balance somatic mutations, this drawback is compensated by a high metabolic redundancy (Lang et al. 2005), whole genome duplications (Rensing et al. 2007), and the arrest of the cell cycle after DNA synthesis in the G2 phase (Schween et al. 2003), combined with efficient DNA repair mechanisms such as homologous recombination (Kamisugi et al. 2006). develop on the apex of the gametophores. Male gametangia (antheridia) release flagellate gametes that need a water film to travel to the female gametangia (archaegonia). From the diploid (2n) zygote, a sporophyte is formed on top of the gametophyte, which in turn forms spores (1n) by meiosis. Ripe sporophytes open by rupture and release spores which germinate to generate protonema. Scale bars: a $6 \mu \mathrm{m}$, b $50 \mu \mathrm{m}$, c $1 \mathrm{~mm}, \mathbf{d} 500 \mu \mathrm{m}$, e $200 \mu \mathrm{m}, \mathbf{f} 100 \mu \mathrm{m}$

\subsection{P. patens exhibits several growth modes and a high} regeneration capacity

The juvenile stage of gametophyte development, the filamentous protonema (Fig. 1b) is growing by perpetually dividing meristematic tip cells, whereas the adult stage, the gametophores (Fig. 1c), possess a three-faced apical meristematic cell which supports the formation of leafy shoots (Aoyama et al. 2012; Harrison et al. 2009). The role and response of hormones during the different developmental stages and possible culture conditions are well characterized and reviewed elsewhere (Bonhomme et al. 2013; Decker et al. 2006; Kofuji and Hasebe 2014; Strotbek et al. 2013). For research, moss tissue can easily be cultivated either on agar plates where gametophores are formed within few weeks or as protonema in liquid medium. Cells from a detached leaflet, a protoplast, or a wounded protonema filament undergo reprogramming to a meristematic protonema tip cell without the addition of exogenous hormones (Nishiyama et al. 2012). 
This high regeneration capacity also supports the cultivation of moss tissue in liquid medium using weekly disruption cycles and the easy regeneration of plants from protoplasts. The molecular mechanisms underlying this pluripotency have been investigated and unraveled several key players including a basic helix loop helix transcription factor and two WUSCHEL-related homeobox 13-like genes (Busch et al. 2013; Nishiyama et al. 2012; Sakakibara et al. 2014).

\subsection{Mosses are poikilohydric}

In addition to the distinct dominant generations, mosses and vascular plants differ also in the morphology and consequently in resulting features such as water balance and body height. Moss tissues are mostly only one cell layer thick which makes them poikilohydric organisms. Mosses equilibrate to the humidity of the surrounding environment, in contrast to endohydric vascular plants (Mishler and Oliver 2009). In consequence to changes of humidity, wind, illumination, or temperature, bryophyte species often have to deal with high fluctuations in water content with most species, including P. patens, being dehydration tolerant, whereas some species even being desiccation tolerant (Oliver et al. 2005).

\subsection{Gene targeting in P. patens is facilitated by homologous recombination}

P. patens is amenable to several transformation techniques to generate transient or stable transgenic plants, with polyethylene glycol mediated protoplast transformation being the most commonly used (Cove et al. 2009; Strotbek et al. 2013). RNAi-based procedures and inducible expression systems are established and available (reviewed in Strotbek et al. 2013). However, one of the original reasons to choose P. patens as a model organism was its exceptionally high rate of homologous recombination enabling gene targeting strategies as a tool for reverse genetics (Reski 1998). Similarly, an increased gene targeting efficiency compared to vascular plants, but lower than in P. patens, was reported for the moss C. purpureus (Trouiller et al. 2007).

DNA double strand breaks are in general repaired either by non-homologous end joining (NHEJ) or by homologous recombination (HR). The balance between these two mechanisms can shift, depending on the species and/or the developmental state. In P. patens, the integration of foreign DNA via homologous recombination can occur in frequencies of up to $100 \%$ of successful transformants (Kamisugi et al. 2005). Hereby, the addition of 500-1000 bp of homologous sequence is sufficient to target a DNA construct to a specific genomic locus (Kamisugi et al. 2005). In reverse genetics, this technique is employed to disrupt or completely delete the target gene, resulting in a knock-out, but it can also easily be used to knock-in a reporter at the endogenous locus (Mosquna et al.
2009; Mueller et al. 2014; Schaefer 2002) or to modify a gene on the single base pair level. Thus, proteins with altered amino acid sequence can be generated from the endogenous genomic locus, enabling techniques such as the mutation of specific disulfide bridges or phosphomimetic mutants, similar to techniques used in the model yeast Saccharomyces cerevisiae.

The molecular basis of the high rate of homologous recombination of the "green yeast" P. patens has been the subject of several studies, identifying some important factors (Charlot et al. 2014; Kamisugi et al. 2012), although a complete mechanistic model is still lacking.

\subsection{Extended moss resources: bioinformatics and high throughput data}

Other benefits of the moss model are the increasing resources on the annotation and bioinformatic level. Gene models for $P$. patens are available since the sequencing of the genome (Rensing et al. 2008) and implemented in two organismspecific databases: www.cosmoss.org and http://moss.nibb. ac.jp/. Genome annotation is permanently improved (Zimmer et al. 2013). In addition, moss gene models are well integrated in orthology and phylogenomics databases such as PLAZA, KEGG, and OrthoMCL (Van Bel et al. 2012; Chen et al. 2006; Kanehisa et al. 2014). Comparative studies are also supported by the integration of moss into the Plant Ontology, providing a controlled and structured plant term vocabulary (Cooper et al. 2013). A curated list of ortholog groups of $P$. patens and 28 plant species was published with the current genome annotation (Zimmer et al. 2013), enabling the simultaneous search for homologs in many species, including poplar and papaya.

In recent years, several -omics techniques have added a considerable amount of new data concerning the P. patens metabolome and proteome (Erxleben et al. 2012; Mueller et al. 2014), as well as the transcriptome (Beike et al. 2015b; Cuming et al. 2007; O'Donoghue et al. 2013; Richardt et al. 2010), which can be screened on the Genevestigator transcriptomics platform (Hiss et al. 2014).

At the transcriptome level, additional moss data is available for C. purpureus (Szövényi et al. 2015), and the 1000 Plants (1KP) consortium will add RNA-seq data for 41 moss species in the near future (Matasci et al. 2014).

Moss data on metabolic pathways have been integrated into the Plant Metabolic Network database (Caspi et al. 2007), generating the MossCyc database (http://www.plantcyc. org/). Furthermore, mutants and ecotypes of $P$. patens as well as $F$. hygrometrica can be stored and are available from the International Moss Stock Center (IMSC; http://www. moss-stock-center.org/), employing cryo-preservation (Schulte and Reski 2004).

Thus, the search for moss mutants and for the homologs of genes of interest is facilitated and complemented by 
information on tissue- and development-specific expression as well as functional annotation. Whereas $P$. patens serves as a reference model, the increasing amount of sequence data on other moss species enables broader analyses including different habitats.

\subsection{P patens can serve as a production platform}

An additional use of $P$. patens is its establishment as an expression system for recombinant proteins, particularly with respect to glycosylated biopharmaceuticals. The potential of cultivation in photo-bioreactors under low-cost and standardized conditions with volumes of up to 1001 guarantees a high yield of proteins according to good manufacturing practice guidelines (Decker and Reski 2007; Fischer et al. 2012). Many important recombinant biopharmaceuticals need to undergo post-translational modifications, e.g., glycosylation, which are important for their stability and function in the human body. Therefore, bacterial systems are often excluded for expression (Sola and Griebenow 2010). Plants show a similar glycosylation pattern to humans, though the few occurring differences can be immunogenic in humans. Due to the fast and precise gene manipulation technique based on homologous recombination in P. patens, the humanization of the moss glycosylation pattern is feasible and glycoengineering in moss plants is already quite advanced (reviewed in Decker et al. 2014). To date, several human proteins are produced in moss, e.g., vascular endothelial growth factor (Baur et al. 2005), erythropoietin (Weise et al. 2007), and human complement factor $\mathrm{H}$ (Buettner-Mainik et al. 2011). In addition, moss is used as production platform for secondary metabolites such as terpenoids (Bach et al. 2014).

\section{Current moss research: unraveling plant evolution and utilizing advantages of moss systems}

In this section, we would like to illustrate specific examples for the study of ancestral traits of land plants and comparative analyses employing mosses, as well as highlight some research on moss-specific features (see Fig. 2). Most of the presented studies listed below use techniques such as phylogenomics, gene knock-out, and overexpression or complementation experiments between different species. In order to facilitate to start working with moss, we provide an overview of the current knowledge regarding moss physiology, especially integrating research areas with potential links to tree physiology. Thus, we present examples of how mosses were used to establish evolutionary relationships in gene families and how special molecular biology techniques applicable to mosses can support the characterization of target proteins in single protein and high-throughput studies.
3.1 Several regulatory pathways evolved in the common ancestor of land plants

Many hormone systems were already established in early land plants and subsequently adapted, and are thus conserved on the molecular level in mosses and vascular plants. The ancient pathways for auxin (Bennett et al. 2014a, 2014b; Finet and Jaillais 2012; Paponov et al. 2009), cytokinin (Lindner et al. 2014; Pils and Heyl 2009; von Schwartzenberg et al. 2007), and ethylene (Yasumura et al. 2012) were investigated with respect to their corresponding transporters, biosynthesis, and signaling pathways. Further, moss is lacking essential characteristics of the classical gibberellin signaling pathway, although it responds to external gibberellin treatment (Vandenbussche et al. 2007). The abiotic stress response is highly conserved within land plant plants, employing abscisic acid and orthologous transcriptional regulators (Beckett et al. 2000; Khandelwal et al. 2010).

Moreover, the conservation of certain developmental processes, which seem to be associated to early land plant evolution, is a topic of current research. The development of chloroplasts is for example regulated by the GOLDEN2-LIKE transcription factors in angiosperms as well as in mosses, but cannot be found in Chlamydomonas reinhardtii (Yasumura et al. 2005).

In land plants, mutations in the organellar genomes are counterbalanced by the "RNA-editing" mechanism which mediates base exchanges on organellar transcripts. The number of editing sites per gene and specificity of the editing factors, the pentatricopeptide repeat proteins (PPR), can vary between even closely related (moss) species and seems to follow a dynamic evolutionary process (O'Toole et al. 2008; Rüdinger et al. 2012). In flowering plants, up to 500 RNA editing sites were identified in their organelle transcripts, whereas in contrast only 11 sites were found in P. patens mitochondria (Rüdinger et al. 2009).

Interestingly, the gene regulation system including NAC transcription factors which are responsible for the formation of water-conducting cells can be found in vascular and nonvascular plants, but operating in the sporophytic (Yamaguchi et al. 2011) or in the gametophytic generation (Xu et al. 2014), respectively.

In contrast, stomata are present only in the sporophytic generation of mosses and seed plants and operate with a highly conserved guard cell control mechanism, as the involved moss homolog can complement the Arabidopsis thaliana mutant (Chater et al. 2011).

3.2 Moss is amenable to fundamental research in cell biology

The amenability of $P$. patens to microscopy coupled with the knock-in of fluorescent reporters via gene targeting to specific loci can be used for the investigation of fundamental cell 


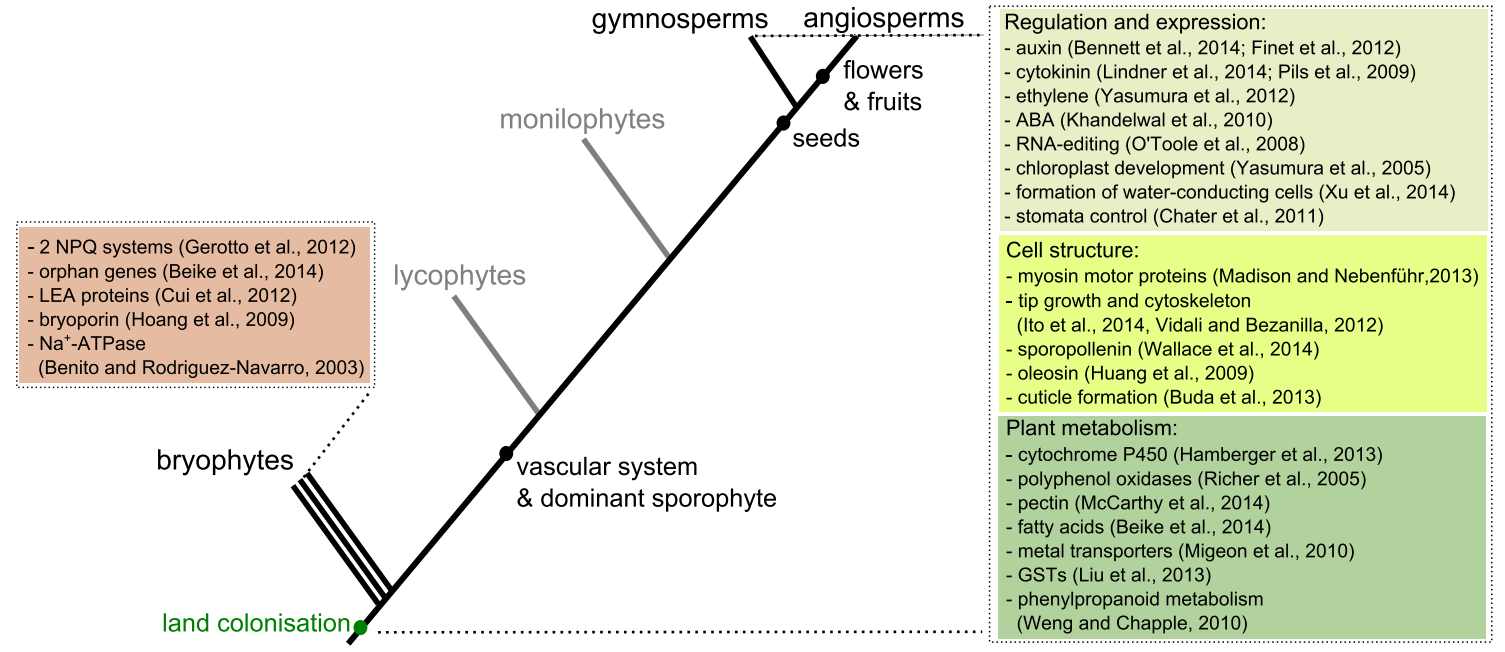

Fig. 2 Evolutionary novelty and conservation investigated using Physcomitrella patens. The main lineages of land plants are depicted in an evolutionary tree. Bryophytes are a paraphyletic group, depicted as three separate lineages in the figure, encompassing the liverworts, mosses, and hornworts. Physcomitrella patens is a model moss. On the

biological questions. As moss protonema filaments elongate by tip growth, as root hairs and pollen tubes in flowering plants, the role of the cytoskeleton and associated factors has been investigated intensively (Finka et al. 2008; Furt et al. 2013; Vidali and Bezanilla 2012). The function of different types of myosin motor proteins were recently analyzed, confirming their conserved function in growth, organelle shape, and actin organization (Madison and Nebenführ 2013), but also identifying a novel role in cell division (Wu and Bezanilla 2014). In addition, the role of the conserved Rop/RAC signaling module in moss tip growth was established (Ito et al. 2014).

Furthermore, the post-translational modification prenylation was shown to be necessary for moss cell differentiation and the establishment of polarity (Thole et al. 2014). Cell polarity as well as organelle morphology and dynamics were also investigated at the subcellular level (Furt et al. 2012; Mueller et al. 2014), including the FtsZ protein family of plastid division factors (Martin et al. 2009). By employing quantitative proteomics techniques such as metabolic labeling with a heavy nitrogen isotope, organellar proteomes were characterized (Mueller et al. 2014). In organelle biology and protein targeting, mosses serve as valuable reference (Xu et al. 2013).

In addition to intracellular communication, intercellular communication via plasmodesmata was visualized by stable transgenic moss lines expressing a photoconvertible fluorescent protein (Kitagawa and Fujita 2013).

Moreover, P. patens is to date the most basal land plant possessing oil bodies for energy storage, reflected by the presence of oleosin genes (Huang et al. 2009).

Thus, quantitative high-throughput analyses for metabolites or proteins are readily available for moss cultures. Moreover, the one-cell-layer-thick moss tissues offer a unique one hand, several studies investigate moss-specific traits (red box) often related to the resilience of moss to environmental conditions. On the other hand, early adaptations of land plants and functional evolution of gene families can be analyzed by comparative studies between mosses and vascular plants (green boxes)

microscopy platform coupled with ease of protein tagging via homologous recombination. These features and techniques could be used to investigate questions of molecular forest research, such as protein modifications and stability, the regulation of cell and organelle signaling, and redox homeostasis.

3.3 Mosses harbor novel enzymatic functions and can be a model for the early adaptations of metabolism to the life on land

While development and body plan underwent large modifications during land plant evolution, many metabolic pathways evolved early and are already present in mosses. The partitioning of metabolism between cell organelles is largely conserved between $P$. patens and flowering plants (Mueller et al. 2014), with some exceptions (Birke et al. 2012). Sometimes even algal and vascular plant features are combined in mosses, as it is the case for the mechanism of nonphotochemical quenching (NPQ), used in plants for converting excess energy produced by photosynthesis (Gerotto et al. 2012).

In early land plants, several cell structures and their corresponding biosynthetic pathways were adapted to the altered environment with increased abiotic stress frequency. Thus, a waxy cuticle with a similar composition protects mosses and seed plants from dehydration, with the plasma membrane transporter involved in its formation being functionally conserved during evolution (Buda et al. 2013). Reproductive propagules in land plants, i.e., spores and pollen, are protected by a tough sporopollenin wall. The respective moss and angiosperm homologs of the sporopollenin biosynthesis gene MALE STERILITY2 (MS2) exhibit a very similar function in 
spore and pollen formation, respectively. However, the moss MS2 gene did not complement the angiosperm mutant, implying functional specialization after the transfer of sporopollenin from spores to pollen (Wallace et al. 2014).

In addition, the genes responsible for the biosynthesis and modification of the cell wall component pectin share a common ancestor in mosses and vascular plants (McCarthy et al. 2014). In order to protect the early land plants from UV radiation, secondary metabolism diversified and phenylpropanoid metabolism emerged (Weng and Chapple 2010). In vascular plants, the phenylpropanoid polymer lignin enabled the evolution of large plant bodies and tracheids by reinforcing and waterproofing the cell wall. In mosses, only soluble phenylpropanoids are known, though homologs of the biosynthetic enzymes producing the lignin monomers $p$-coumaryl alcohol and coniferyl-alcohol are present (Weng and Chapple 2010). Among other reactions, enzymes of the cytochromes P450 enzyme family participate in monolignol biosynthesis by catalyzing the hydroxylation of the aromatic ring. The important role of the P450 enzyme family, contributing to the diversity of plant compounds, is reflected in the increasing number of encoded genes during plant evolution, e.g., in P. patens with 71 and A. thaliana with 245 genes (Hamberger and Bak 2013). An opposite effect was reported for putative genes encoding polyphenol oxidases (PPO) which are responsible for the browning reactions in fruits. Starting in 2005 with the first characterization of a single PPO gene in P. patens (Richter et al. 2005), the release of the genome resulted in 13 putative genes encoding for PPOs, whereas for example in A. thaliana, no homologs were identified (Tran et al. 2012).

Polyunsaturated fatty acids (PUFAs) are important components in the cell for signaling, hormone biosynthesis, and membrane formation. Compared to higher plants, P. patens and other mosses possess high amounts of long PUFAs, whose profile is depending on the developmental stage of the plant (Beike et al. 2014). This difference is based on the existence of several desaturases as well as elongases in moss which were lost in angiosperm evolution and catalyze alternative pathways in the biosynthesis of these fatty acids (Eiamsa-ard et al. 2013; Girke et al. 1998; Kaewsuwan et al. 2006; Zank et al. 2002).

In order to track gene family evolution and function on the sequence level, phylogenomics, i.e., phylogenetic analyses based on sequence comparisons between many plant genomes, is frequently used. Thus, two novel classes of the large gene family of Glutathione-S-Transferases were identified in P. patens, whereas one of the most abundant classes in vascular plants, tau GSTs, was not found (Liu et al. 2013). These enzymes are important players in oxidative stress metabolism and detoxification (see review Jacquot et al. in the same issue).

Furthermore, the types and subfamilies of the land-plantspecific transcription factor AT-Hook Motif Nuclear Localized (AHL) gene family (Zhao et al. 2014) or metal transporters (Migeon et al. 2010) were analyzed, including sequences of Physcomitrella, Arabidopsis, poplar, and many other species. Hence, phylogenomic studies including nonvascular plants give insights into the mechanisms of gene family evolution leading to functional and regulatory diversification (Mueller et al. 2014; Rensing et al. 2007). This approach can be extended to the analysis of subcellular protein compartmentation and protein targeting (Mueller et al. 2014; $\mathrm{Xu}$ et al. 2013).

\subsection{Mosses employ several strategies to increase stress} tolerance

Form and function of mosses entail survival strategies which are thought to be similar to the early land plants and have been lost or adapted in endohydric vascular plants (Oliver et al. 2005). Research on vegetative and seed drought resistance has used mosses such as the desiccation-tolerant Tortula ruralis as reference (Farrant and Moore 2011). Thus, the ecophysiology of mosses is interesting at the molecular, biochem$\mathrm{ical}$, and whole plant level in order to identify alternative stress resistance mechanisms. Especially with regard to the progressing climate change, it is crucial to get insights into the resilience mechanisms of mosses (Peñuelas et al. 2013).

In the last decade, several studies have investigated the response of $P$. patens to abiotic stresses such as light quality and quantity (Alboresi et al. 2010; Wolf et al. 2010), temperature stress (Beike et al. 2015b; Bhyan et al. 2012; Chang et al. 2014), and osmotic stress (Cuming et al. 2007; Frank et al. 2005; Khandelwal et al. 2010). P. patens is dehydrationtolerant but can become desiccation- and freezing-tolerant by pre-treatment with ABA (Khandelwal et al. 2010; Nagao et al. 2005). Whereas abiotic stress signaling seems largely conserved between mosses and flowering plants (Khandelwal et al. 2010; Komatsu et al. 2013; Richardt et al. 2010), several studies report on so-called orphan, non-characterized stress responsive moss genes and proteins (Beike et al. 2015b; Cui et al. 2012).

To date, most attention has been paid to the mechanisms by which mosses master the cellular challenges during dehydration/rehydration and freezing, sometimes also employing ABA or salt treatment (Cui et al. 2012; Cuming et al. 2007; Hiss et al. 2014; Nagao et al. 2005; Oliver et al. 2005). Results include the avoidance of stress by downregulation of photosynthesis (Cuming et al. 2007; Hiss et al. 2014) and the rapid upregulation of protective mechanism for photosynthesis, membranes and protein folding (Azzabi et al. 2012; Hiss et al. 2014; Ruibal et al. 2013). At the metabolic level, free soluble sugars, such as trehanderose, are accumulated to increase the intracellular osmolarity and counterbalance water-loss (Nagao et al. 2005, 2006). At the transcript as well as at the protein level, chaperones such as LEA (late embryogenesis abundant) proteins, also called dehydrins or rehydrins, play prominent roles, though their exact molecular 
function is often still unclear. Later during land plant evolution, LEA protein function was probably adapted to the desiccation of seeds (Cui et al. 2012; Oliver et al. 2005). Functional studies of mutants confirmed the importance of some dehydrins in the moss response to salt and osmotic stress (Ruibal et al. 2012; Saavedra et al. 2006). Two moss dehydrins did also confer increased stress tolerance to Arabidopsis, when overexpressed (Ruibal et al. 2012). In the desiccation-tolerant moss $T$. ruralis, rehydrin mRNAs stored in messenger ribonucleoprotein particles (mRNPs) during drying enable a fast recovery from desiccation (Wood and Oliver 1999).

A remnant of a horizontal gene transfer of metazoans to early land plants may be the presence of a "bryoporin" in P. patens, a putative pore-forming stress-induced actinoporin (Hoang et al. 2009). The high salt tolerance in moss was shown to involve specific $\mathrm{Ca}^{2+}$ signatures (Qudeimat et al. 2008). Further, in contrast to flowering plants, mosses possess $\mathrm{Na}^{+}$-ATPases to limit $\mathrm{Na}^{+}$toxicity (Benito and RodríguezNavarro 2003; Lunde et al. 2007). Further, the function of a $\mathrm{Na}^{+} / \mathrm{H}^{+}$antiporter present in seed plants and mosses was clarified using targeted knock-outs in P. patens (Fraile-Escanciano et al. 2010).

In order to fully understand protective mechanisms against abiotic stress in moss, the increasing amount of transcriptome and proteome data needs to be complemented by functional studies on the contribution of single genes and by the characterization of moss-specific orphan genes. However, it is already clear that moss cells respond specifically, and according to their developmental state, at many different levels to adjust cell morphology and metabolism to the corresponding stress challenge. Thus, the ecophysiology of mosses from different habitats and the key pathways of their stress tolerance are still under investigation with mosses providing morphologically simple model systems for comparative and biotechnological studies.

\section{Conclusion}

Mosses are omnipresent extant relatives of early land plants whose ecological significance is often not well characterized. Thus, the investigation of moss biology offers insights into plant evolution, plant survival strategies as well as an often simpler experimental system with valuable molecular biology tools.

At the moment $P$. patens constitutes the most developed model moss regarding molecular biology techniques, bioinformatics as well as available physiology data. With the amount and quality of genome annotation, transcriptomics, and proteomics data still increasing, this model moss will serve as a platform for many exciting de novo studies, as well as a reference for many other sequencing projects of mosses from different habitats, as, e.g., peat mosses.

The amenability of several bryophytes to single-base-pair exact changes and knock-in of tags in the genome is still a major advantage for many studies envisaging custom mutations and tracking of tagged proteins. With more and more puzzle pieces of land plant evolution unraveled, the right choice of complementary model systems to seed plants becomes easier. Especially organelle biology, cell polarity, stress tolerance, and secondary metabolism represent shared topics in moss and forest research. Thus, mosses represent alternative model systems for many molecular biology studies.

By studying moss biology, we can learn more about fundamental questions of plant physiology and evolution and will further strive to integrate this knowledge on the macro-scale in the study of ecosystems.

Acknowledgments D.D.G. is supported by a grant overseen by the French National Research Agency (ANR) as part of the "Investissements d'Avenir" program (ANR-11-LABX-0002-01, Lab of Excellence ARBRE). Her PhD grant is from the French MENRT. Additionally, this work was funded by the Excellence Initiative of the German Federal and State Governments (EXC 294 BIOSS and GSC-4, Spemann Graduate School of Biology and Medicine). We thank Anne Katrin Prowse and Dr. Hugues Renault for proofreading the manuscript.

We apologize to our colleagues whose work could not be included due to space constraints.

\section{References}

Alboresi A, Gerotto C, Giacometti GM, Bassi R, Morosinotto T (2010) Physcomitrella patens mutants affected on heat dissipation clarify the evolution of photoprotection mechanisms upon land colonization. Proc Natl Acad Sci U S A 107:11128-11133

Aoyama T, Hiwatashi Y, Shigyo M, Kofuji R, Kubo M, Ito M, Hasebe M (2012) AP2-type transcription factors determine stem cell identity in the moss Physcomitrella patens. Dev Camb Engl 139:3120-3129

Azzabi G, Pinnola A, Betterle N, Bassi R, Alboresi A (2012) Enhancement of non-photochemical quenching in the bryophyte Physcomitrella patens during acclimation to salt and osmotic stress. Plant Cell Physiol 53:1815-1825

Bach SS, King BC, Zhan X, Simonsen HT, Hamberger B (2014) Heterologous stable expression of terpenoid biosynthetic genes using the moss Physcomitrella patens. In: Rodríguez-Concepción M (ed) Plant Isoprenoids. Springer, New York, pp 257-271

Bates JW (2009) Mineral nutrition and substratum ecology. In: Goffinet B, Shaw AJ (eds) Bryophyte Biology. Cambridge University Press, New York, pp 299-356

Baur A, Reski R, Gorr G (2005) Enhanced recovery of a secreted recombinant human growth factor using stabilizing additives and by coexpression of human serum albumin in the moss Physcomitrella patens. Plant Biotechnol J 3:331-340

Beckett RP, Csintalan Z, Tuba Z (2000) ABA treatment increases both the desiccation tolerance of photosynthesis, and nonphotochemical quenching in the moss Atrichum undulatum. Plant Ecol 151:65-71

Beike AK, Jaeger C, Zink F, Decker EL, Reski R (2014) High contents of very long-chain polyunsaturated fatty acids in different moss species. Plant Cell Rep 33:245-254 
Beike AK, Spagnuolo V, Lüth V, Steinhart F, Ramos-Gómez J, Krebs M, Adamo P, Rey-Asensio AI, Fernández JA, Giordano S et al (2015a) Clonal in vitro propagation of peat mosses (Sphagnum L.) as novel green resources for basic and applied research. Plant Cell Tissue Organ Cult 120:1037-1049

Beike AK, Lang D, Zimmer AD, Wüst F, Trautmann D, Wiedemann G, Beyer P, Decker EL, Reski R (2015b) Insights from the cold transcriptome of Physcomitrella patens: global specialization pattern of conserved transcriptional regulators and identification of orphan genes involved in cold acclimation. New Phytol 205:869-881

Benito B, Rodríguez-Navarro A (2003) Molecular cloning and characterization of a sodium-pump ATPase of the moss Physcomitrella patens. Plant J Cell Mol Biol 36:382-389

Bennett T, Brockington SF, Rothfels C, Graham SW, Stevenson D, Kutchan T, Rolf M, Thomas P, Wong GK-S, Leyser O et al (2014a) Paralogous radiations of PIN proteins with multiple origins of noncanonical PIN structure. Mol Biol Evol 31:2042-2060

Bennett TA, Liu MM, Aoyama T, Bierfreund NM, Braun M, Coudert Y, Dennis RJ, O'Connor D, Wang XY, White CD et al (2014b) Plasma membrane-targeted PIN proteins drive shoot development in a moss. Curr Biol CB 24:2776-2785

Bhyan SB, Minami A, Kaneko Y, Suzuki S, Arakawa K, Sakata Y, Takezawa D (2012) Cold acclimation in the moss Physcomitrella patens involves abscisic acid-dependent signaling. J Plant Physiol 169:137-145

Birke H, Müller SJ, Rother M, Zimmer AD, Hoernstein SNW, Wesenberg D, Wirtz M, Krauss G-J, Reski R, Hell R (2012) The relevance of compartmentation for cysteine synthesis in phototrophic organisms. Protoplasma 249:S147-S155

Bonhomme S, Nogué F, Rameau C, Schaefer DG (2013) Usefulness of Physcomitrella patens for studying plant organogenesis. Methods Mol Biol Clifton NJ 959:21-43

Buda GJ, Barne WJ, Fich EA, Park S, Yeats TH, Zhao L, Domozych DS, Rose JKC (2013) An ATP binding cassette transporter is required for cuticular wax deposition and desiccation tolerance in the moss Physcomitrella patens. Plant Cell 25:4000-4013

Buettner-Mainik A, Parsons J, Jerome H, Hartmann A, Lamer S, Schaaf A, Schlosser A, Zipfel PF, Reski R, Decker EL (2011) Production of biologically active recombinant human factor $\mathrm{H}$ in Physcomitrella. Plant Biotechnol J 9:373-383

Busch H, Boerries M, Bao J, Hanke ST, Hiss M, Tiko T, Rensing SA (2013) Network theory inspired analysis of time-resolved expression data reveals key players guiding $P$. patens stem cell development. PLoS One 8:e60494

Caspi R, Foerster H, Fulcher CA, Kaipa P, Krummenacker M, Latendresse M, Paley S, Rhee SY, Shearer AG, Tissier C et al (2007) The MetaCyc database of metabolic pathways and enzymes and the BioCyc collection of pathway/genome databases. Nucleic Acids Res 36:D623-D631

Chang CY, Lin WD, Tu SL (2014) Genome-wide analysis of heatsensitive alternative splicing in Physcomitrella patens. Plant Physiol 165:826-840

Charlot F, Chelysheva L, Kamisugi Y, Vrielynck N, Guyon A, Epert A, Guin SL, Schaefer DG, Cuming AC, Grelon M et al (2014) RAD51B plays an essential role during somatic and meiotic recombination in Physcomitrella. Nucleic Acids Res 42:11965-11978

Chater C, Kamisugi Y, Movahedi M, Fleming A, Cuming AC, Gray JE, Beerling DJ (2011) Regulatory mechanism controlling stomatal behavior conserved across 400 million years of land plant evolution. Curr Biol 21:1025-1029

Chen F, Mackey AJ, Stoeckert CJ Jr, Roos DS (2006) OrthoMCL-DB: querying a comprehensive multi-species collection of ortholog groups. Nucleic Acids Res 34:D363-D368

Cooper L, Walls RL, Elser J, Gandolfo MA, Stevenson DW, Smith B, Preece J, Athreya B, Mungall CJ, Rensing S et al (2013) The Plant
Ontology as a tool for comparative plant anatomy and genomic analyses. Plant Cell Physiol 54(2):e1

Cove D (2005) The moss Physcomitrella patens. Annu Rev Genet 39: 339-358

Cove DJ, Perroud P-F, Charron AJ, McDaniel SF, Khandelwal A, Quatrano RS (2009) The moss Physcomitrella patens: a novel model system for plant development and genomic studies. Cold Spring Harb Protoc. doi:10.1101/pdb.emo115

Cui S, Hu J, Guo S, Wang J, Cheng Y, Dang X, Wu L, He Y (2012) Proteome analysis of Physcomitrella patens exposed to progressive dehydration and rehydration. J Exp Bot 63:711-726

Cuming AC, Cho SH, Kamisugi Y, Graham H, Quatrano RS (2007) Microarray analysis of transcriptional responses to abscisic acid and osmotic, salt, and drought stress in the moss, Physcomitrella patens. New Phytol 176:275-287

Decker EL, Reski R (2007) Moss bioreactors producing improved biopharmaceuticals. Curr Opin Biotechnol 18:393-398

Decker EL, Frank W, Sarnighausen E, Reski R (2006) Moss systems biology en route: phytohormones in Physcomitrella development. Plant Biol Stuttg Ger 8:397-405

Decker EL, Parsons J, Reski R (2014) Glyco-engineering for biopharmaceutical production in moss bioreactors. Plant Physiol 5:346

DeLuca TH, Zackrisson O, Nilsson M-C, Sellstedt A (2002) Quantifying nitrogen-fixation in feather moss carpets of boreal forests. Nature 419:917-920

Eiamsa-ard P, Kanjana-Opas A, Cahoon EB, Chodok P, Kaewsuwan S (2013) Two novel Physcomitrella patens fatty acid elongases (ELOs): identification and functional characterization. Appl Microbiol Biotechnol 97:3485-3497

Erxleben A, Gessler A, Vervliet-Scheebaum M, Reski R (2012) Metabolite profiling of the moss Physcomitrella patens reveals evolutionary conservation of osmoprotective substances. Plant Cell Rep 31:427-436

Farge CL, Williams KH, England JH (2013) Regeneration of Little Ice Age bryophytes emerging from a polar glacier with implications of totipotency in extreme environments. Proc Natl Acad Sci 110:98399844

Farrant JM, Moore JP (2011) Programming desiccation-tolerance: from plants to seeds to resurrection plants. Curr Opin Plant Biol 14:340 345

Finet C, Jaillais Y (2012) Auxology: when auxin meets plant evo-devo. Dev Biol 369:19-31

Finka A, Saidi Y, Goloubinoff P, Neuhaus J-M, Zrÿd J-P, Schaefer DG (2008) The knock-out of ARP3a gene affects F-actin cytoskeleton organization altering cellular tip growth, morphology and development in moss Physcomitrella patens. Cell Motil Cytoskeleton 65: 769-784

Fischer R, Schillberg S, Hellwig S, Twyman RM, Drossard J (2012) GMP issues for recombinant plant-derived pharmaceutical proteins. Biotechnol Adv 30:434-439

Fraile-Escanciano A, Kamisugi Y, Cuming AC, Rodríguez-Navarro A, Benito B (2010) The SOS1 transporter of Physcomitrella patens mediates sodium efflux in planta. New Phytol 188:750-761

Frank W, Ratnadewi D, Reski R (2005) Physcomitrella patens is highly tolerant against drought, salt and osmotic stress. Planta 220:384-394

Furt F, Lemoi K, Tüzel E, Vidali L (2012) Quantitative analysis of organelle distribution and dynamics in Physcomitrella patens protonemal cells. BMC Plant Biol 12:70

Furt F, Liu Y-C, Bibeau JP, Tüzel E, Vidali L (2013) Apical myosin XI anticipates F-actin during polarized growth of Physcomitrella patens cells. Plant J 73:417-428

Gerotto C, Alboresi A, Giacometti GM, Bassi R, Morosinotto T (2012) Coexistence of plant and algal energy dissipation mechanisms in the moss Physcomitrella patens. New Phytol 196:763-773 
Girke T, Schmidt H, Zähringer U, Reski R, Heinz E (1998) Identification of a novel D6-acyl-group desaturase by targeted gene disruption in Physcomitrella patens. Plant J 15:39-48

Gradstein SR, Churchill SP, Allen NS (2001) Guide to the bryophytes of tropical America. Botanical Garden Press, New York

Hamberger B, Bak S (2013) Plant P450s as versatile drivers for evolution of species-specific chemical diversity. Philos Trans R Soc B Biol Sci. doi:10.1098/rstb.2012.0426

Harrison CJ, Roeder AHK, Meyerowitz EM, Langdale JA (2009) Local cues and asymmetric cell divisions underpin body plan transitions in the moss Physcomitrella patens. Curr Biol CB 19:461-471

Hiss M, Laule O, Meskauskiene R, Arif M, Decker E, Erxleben A, Frank W, Hanke S, Lang D, Martin A et al (2014) Large scale gene expression profiling data of the model moss Physcomitrella patens help to understand developmental progression, culture and stress conditions. Plant J 79:530-539

Hoang QT, Cho SH, McDaniel SF, Ok SH, Quatrano RS, Shin JS (2009) An actinoporin plays a key role in water stress in the moss Physcomitrella patens. New Phytol 184:502-510

Huang C-Y, Chung C-I, Lin Y-C, Hsing Y-IC, Huang AHC (2009) Oil bodies and oleosins in Physcomitrella possess characteristics representative of early trends in evolution. Plant Physiol 150:1192-1203

Hubers M, Kerp H (2012) Oldest known mosses discovered in Mississippian (late Visean) strata of Germany. Geology 40:755-758

Ito K, Ren J, Fujita T (2014) Conserved function of Rho-related Rop/ RAC GTPase signaling in regulation of cell polarity in Physcomitrella patens. Gene 544:241-247

Jansson S, Douglas CJ (2007) Populus: a model system for plant biology. Annu Rev Plant Biol 58:435-458

Jones CG, Lawton JH, Shachak M (1994) Organisms as ecosystem engineers. Oikos 69:373-386

Kaewsuwan S, Cahoon EB, Perroud P-F, Wiwat C, Panvisavas N, Quatrano RS, Cove DJ, Bunyapraphatsara N (2006) Identification and functional characterization of the moss Physcomitrella patens $\Delta 5$-desaturase gene involved in arachidonic and eicosapentaenoic acid biosynthesis. J Biol Chem 281:21988-21997

Kamisugi Y, Cuming AC, Cove DJ (2005) Parameters determining the efficiency of gene targeting in the moss Physcomitrella patens. Nucleic Acids Res 33(19):e173

Kamisugi Y, Schlink K, Rensing SA, Schween G, von Stackelberg M, Cuming AC, Reski R, Cove DJ (2006) The mechanism of gene targeting in Physcomitrella patens: homologous recombination, concatenation and multiple integration. Nucleic Acids Res 34: 6205-6214

Kamisugi Y, Schaefer DG, Kozak J, Charlot F, Vrielynck N, Holá M, Angelis KJ, Cuming AC, Nogué F (2012) MRE11 and RAD50, but not NBS1, are essential for gene targeting in the moss Physcomitrella patens. Nucleic Acids Res 40:3496-3510

Kanehisa M, Goto S, Sato Y, Kawashima M, Furumichi M, Tanabe M (2014) Data, information, knowledge and principle: back to metabolism in KEGG. Nucleic Acids Res 42:D199-D205

Kenrick P, Crane PR (1997) The origin and early evolution of plants on land. Nature 389:33-39

Khandelwal A, Cho SH, Marella H, Sakata Y, Perroud P-F, Pan A, Quatrano RS (2010) Role of ABA and ABI3 in desiccation tolerance. Science 327:546

Kitagawa M, Fujita T (2013) Quantitative imaging of directional transport through plasmodesmata in moss protonemata via single-cell photoconversion of Dendra2. J Plant Res 126:577-585

Kofuji R, Hasebe M (2014) Eight types of stem cells in the life cycle of the moss Physcomitrella patens. Curr Opin Plant Biol 17:13-21

Komatsu K, Suzuki N, Kuwamura M, Nishikawa Y, Nakatani M, Ohtawa H, Takezawa D, Seki M, Tanaka M, Taji T et al (2013) Group A PP2Cs evolved in land plants as key regulators of intrinsic desiccation tolerance. Nat Commun. doi:10.1038/ncomms3219
Lang D, Eisinger J, Reski R, Rensing SA (2005) Representation and high-quality annotation of the Physcomitrella patens transcriptome demonstrates a high proportion of proteins involved in metabolism in mosses. Plant Biol 7:238-250

Lang D, Weiche B, Timmerhaus G, Richardt S, Riaño-Pachón DM, Corrêa LGG, Reski R, Mueller-Roeber B, Rensing SA (2010) Genome-wide phylogenetic comparative analysis of plant transcriptional regulation: a timeline of loss, gain, expansion, and correlation with complexity. Genome Biol Evol 2:488-503

Lindner A-C, Lang D, Seifert M, Podlesakova K, Novak O, Strnad M, Reski R, von Schwartzenberg K (2014) Isopentenyltransferase-1 (IPT1) knockout in Physcomitrella together with phylogenetic analyses of IPTs provide insights into evolution of plant cytokinin biosynthesis. J Exp Bot 65:2533-2543

Liu Y-J, Han X-M, Ren L-L, Yang H-L, Zeng Q-Y (2013) Functional divergence of the Glutathione S-Transferase supergene family in Physcomitrella patens reveals complex patterns of large gene family evolution in land plants. Plant Physiol 161:773-786

Lunde C, Drew DP, Jacobs AK, Tester M (2007) Exclusion of Na+ via sodium ATPase (PpENA1) ensures normal growth of Physcomitrella patens under moderate salt stress. Plant Physiol 144:1786-1796

Madison SL, Nebenführ A (2013) Understanding myosin functions in plants: are we there yet? Curr Opin Plant Biol 16:710-717

Martin A, Lang D, Hanke ST, Mueller SJX, Sarnighausen E, VervlietScheebaum M, Reski R (2009) Targeted gene knockouts reveal overlapping functions of the five Physcomitrella patens FtsZ isoforms in chloroplast division, chloroplast shaping, cell patterning, plant development, and gravity sensing. Mol Plant 2:1359-1372

Matasci N, Hung L-H, Yan Z, Carpenter EJ, Wickett NJ, Mirarab S, Nguyen N, Warnow T, Ayyampalayam S, Barker M et al (2014) Data access for the 1,000 Plants (1KP) project. Giga Sci 3:17

McCarthy TW, Der JP, Honaas LA, dePamphilis CW, Anderson CT (2014) Phylogenetic analysis of pectin-related gene families in Physcomitrella patens and nine other plant species yields evolutionary insights into cell walls. BMC Plant Biol 14:79

Migeon A, Blaudez D, Wilkins O, Montanini B, Campbell MM, Richaud P, Thomine S, Chalot M (2010) Genome-wide analysis of plant metal transporters, with an emphasis on poplar. Cell Mol Life Sci CMLS 67:3763-3784

Mishler BD, Oliver MJ (2009) Putting Physcomitrella patens on the tree of life: the evolution and ecology of mosses. In: Knight C, Perrroud P-F, Cove D (eds) The moss Physcomitrella patens. Annual Plant Reviews, vol 36. Wiley-Blackwell, pp 1-15

Mosquna A, Katz A, Decker EL, Rensing SA, Reski R, Ohad N (2009) Regulation of stem cell maintenance by the Polycomb protein FIE has been conserved during land plant evolution. Development 136: 2433-2444

Mueller SJ, Lang D, Hoernstein SNW, Lang EGE, Schuessele C, Schmidt A, Fluck M, Leisibach D, Niegl C, Zimmer AD et al (2014) Quantitative analysis of the mitochondrial and plastid proteomes of the moss Physcomitrella patens reveals protein macrocompartmentation and microcompartmentation. Plant Physiol 164:2081-2095

Müller B, Grossniklaus U (2010) Model organisms - a historical perspective. J Proteomics 73:2054-2063

Nagao M, Minami A, Arakawa K, Fujikawa S, Takezawa D (2005) Rapid degradation of starch in chloroplasts and concomitant accumulation of soluble sugars associated with ABA-induced freezing tolerance in the moss Physcomitrella patens. J Plant Physiol 162:169-180

Nagao M, Oku K, Minami A, Mizuno K, Sakurai M, Arakawa K, Fujikawa S, Takezawa D (2006) Accumulation of theanderose in association with development of freezing tolerance in the moss Physcomitrella patens. Phytochemistry 67:702-709

Nishiyama T, Miyawaki K, Ohshima M, Thompson K, Nagashima A, Hasebe M, Kurata T (2012) Digital gene expression profiling by 5'- 
end sequencing of cDNAs during reprogramming in the moss Physcomitrella patens. PLoS One 7(5):e36471

O'Donoghue M-T, Chater C, Wallace S, Gray JE, Beerling DJ, Fleming AJ (2013) Genome-wide transcriptomic analysis of the sporophyte of the moss Physcomitrella patens. J Exp Bot 64:3567-3581

Oliver MJ, Velten J, Mishler BD (2005) Desiccation tolerance in bryophytes: a reflection of the primitive strategy for plant survival in dehydrating habitats? Integr Comp Biol 45:788-799

O'Toole N, Hattori M, Andres C, Iida K, Lurin C, Schmitz-Linneweber C, Sugita M, Small I (2008). On the expansion of the pentatricopeptide repeat gene family in plants. Mol Biol Evol 25(6):1120-1128

Paponov IA, Teale W, Lang D, Paponov M, Reski R, Rensing SA, Palme $\mathrm{K}$ (2009) The evolution of nuclear auxin signalling. BMC Evol Biol 9:126

Peñuelas J, Sardans J, Estiarte M, Ogaya R, Carnicer J, Coll M, Barbeta A, Rivas-Ubach A, Llusià J, Garbulsky M et al (2013) Evidence of current impact of climate change on life: a walk from genes to the biosphere. Glob Change Biol 19:2303-2338

Pils B, Heyl A (2009) Unraveling the evolution of cytokinin signaling. Plant Physiol 151:782-791

Plackett ARG, Huang L, Sanders HL, Langdale JA (2014) Highefficiency stable transformation of the model fern species Ceratopteris richardii via microparticle bombardment. Plant Physiol 165:3-14

Qudeimat E, Faltusz AMC, Wheeler G, Lang D, Holtorf H, Brownlee C, Reski R, Frank W (2008) A PIIB-type Ca2+-ATPase is essential for stress adaptation in Physcomitrella patens. Proc Natl Acad Sci U S A 105:19555-19560

Rensing SA, Ick J, Fawcett JA, Lang D, Zimmer A, Van de Peer Y, Reski $\mathrm{R}$ (2007) An ancient genome duplication contributed to the abundance of metabolic genes in the moss Physcomitrella patens. BMC Evol Biol 7:130

Rensing SA, Lang D, Zimmer AD, Terry A, Salamov A, Shapiro H, Nishiyama T, Perroud P-F, Lindquist EA, Kamisugi Y et al (2008) The Physcomitrella genome reveals evolutionary insights into the conquest of land by plants. Science 319:64-69

Reski R (1998) Physcomitrella and Arabidopsis: the David and Goliath of reverse genetics. Trends Plant Sci 3:209-210

Richardt S, Timmerhaus G, Lang D, Qudeimat E, Corrêa LGG, Reski R, Rensing SA, Frank W (2010) Microarray analysis of the moss Physcomitrella patens reveals evolutionarily conserved transcriptional regulation of salt stress and abscisic acid signalling. Plant Mol Biol 72:27-45

Richter H, Lieberei R, von Schwartzenberg K (2005) Identification and characterisation of a bryophyte polyphenol oxidase encoding gene from Physcomitrella patens. Plant Biol 7:283-291

Roads E, Longton RE, Convey P (2014) Millennial timescale regeneration in a moss from Antarctica. Curr Biol CB 24:R222-R223

Rousk K, Davey LJ, DeLuca TH (2013) Moss-cyanobacteria associations as biogenic sources of nitrogen in boreal forest ecosystems. Front Microbiol 4:150

Rüdinger M, Funk HT, Rensing SA, Maier UG, Knoop V (2009) RNA editing: only eleven sites are present in the Physcomitrella patens mitochondrial transcriptome and a universal nomenclature proposal. Mol Genet Genomics 281:473-481

Rüdinger M, Volkmar U, Lenz H, Groth-Malonek M, Knoop V (2012) Nuclear DYW-type PPR gene families diversify with increasing RNA editing frequencies in liverwort and moss mitochondria. J Mol Evol 74:37-51

Ruibal C, Salamó IP, Carballo V, Castro A, Bentancor M, Borsani O, Szabados L, Vidal S (2012) Differential contribution of individual dehydrin genes from Physcomitrella patens to salt and osmotic stress tolerance. Plant Sci Int J Exp Plant Biol 190:89-102

Ruibal C, Castro A, Carballo V, Szabados L, Vidal S (2013) Recovery from heat, salt and osmotic stress in Physcomitrella patens requires a functional small heat shock protein PpHsp16.4. BMC Plant Biol 13: 174

Saavedra L, Svensson J, Carballo V, Izmendi D, Welin B, Vidal S (2006) A dehydrin gene in Physcomitrella patens is required for salt and osmotic stress tolerance. Plant J Cell Mol Biol 45:237-249

Sakakibara K, Ando S, Yip HK, Tamada Y, Hiwatashi Y, Murata T, Deguchi H, Hasebe M, Bowman JL (2013) KNOX2 genes regulate the haploid-to-diploid morphological transition in land plants. Science 339:1067-1070

Sakakibara K, Reisewitz P, Aoyama T, Friedrich T, Ando S, Sato Y, Tamada Y, Nishiyama T, Hiwatashi Y, Kurata T et al (2014) WOX13-like genes are required for reprogramming of leaf and protoplast cells into stem cells in the moss Physcomitrella patens. Development 141:1660-1670

Schaefer DG (2002) A new moss genetics: targeted mutagenesis in Physcomitrella patens. Annu Rev Plant Biol 53:477-501

Schulte J, Reski R (2004) High throughput cryopreservation of 140,000 Physcomitrella patens mutants. Plant Biol 6:119-127

Schween G, Gorr G, Hohe A, Reski R (2003) Unique tissue-specific cell cycle in Physcomitrella. Plant Biol 5:50-58

Shaw AJ, Cox CJ, Boles SB (2003) Polarity of peatmoss (Sphagnum) evolution: who says bryophytes have no roots? Am J Bot 90:17771787

Sola RJ, Griebenow K (2010) Glycosylation of therapeutic proteins: an effective strategy to optimize efficacy. BioDrugs Clin Immunother Biopharm Gene Ther 24:9-21

Strotbek C, Krinninger S, Frank W (2013) The moss Physcomitrella patens: methods and tools from cultivation to targeted analysis of gene function. Int J Dev Biol 57:553-564

Szövényi P, Perroud P-F, Symeonidi A, Stevenson S, Quatrano RS, Rensing SA, Cuming AC, McDaniel SF (2015) De novo assembly and comparative analysis of the Ceratodon purpureus transcriptome. Mol Ecol Resour 15:203-215

Thole JM, Perroud P-F, Quatrano RS, Running MP (2014) Prenylation is required for polar cell elongation, cell adhesion, and differentiation in Physcomitrella patens. Plant J Cell Mol Biol 78:441-451

Tran LT, Taylor JS, Constabel CP (2012) The polyphenol oxidase gene family in land plants: lineage-specific duplication and expansion. BMC Genomics 13:395

Trouiller B, Charlot F, Choinard S, Schaefer DG, Nogué F (2007) Comparison of gene targeting efficiencies in two mosses suggests that it is a conserved feature of bryophyte transformation. Biotechnol Lett 29:1591-1598

Turetsky MR (2003) The role of bryophytes in carbon and nitrogen cycling. Bryologist 106:395-409

Turetsky MR, Bond-Lamberty B, Euskirchen E, Talbot J, Frolking S, McGuire AD, Tuittila E-S (2012) The resilience and functional role of moss in boreal and arctic ecosystems. New Phytol 196:49-67

van Bel M, Proost S, Wischnitzki E, Movahedi S, Scheerlinck C, Van de Peer Y, Vandepoele K (2012) Dissecting plant genomes with the PLAZA comparative genomics platform. Plant Physiol 158:590 600

Vandenbussche F, Fierro AC, Wiedemann G, Reski R, Van Der Straeten D (2007) Evolutionary conservation of plant gibberellin signalling pathway components. BMC Plant Biol 7:65

Vidali L, Bezanilla M (2012) Physcomitrella patens: a model for tip cell growth and differentiation. Curr Opin Plant Biol 15:625-631

Vitt DH, Wieder RK (2009) The structure and function of bryophytedominated peatlands. In: Goffinet B, Shaw AJ (eds) Bryophyte biology. Cambridge University Press, New York, pp 357-392

von Schwartzenberg K, Nunez MF, Blaschke H, Dobrev PI, Novak O, Motyka V, Strnad M (2007) Cytokinins in the bryophyte Physcomitrella patens: analyses of activity, distribution, and cytokinin oxidase/dehydrogenase overexpression reveal the role of extracellular cytokinins. Plant Physiol 145:786-800 
Wallace S, Chater CC, Kamisugi Y, Cuming AC, Wellman CH, Beerling DJ, Fleming AJ (2014) Conservation of Male Sterility 2 function during spore and pollen wall development supports an evolutionarily early recruitment of a core component in the sporopollenin biosynthetic pathway. New Phytol 205(1):390-401

Weise A, Altmann F, Rodriguez-Franco M, Sjoberg ER, Bäumer W, Launhardt H, Kietzmann M, Gorr G (2007) High-level expression of secreted complex glycosylated recombinant human erythropoietin in the Physcomitrella $\Delta$-fuc-t $\Delta$-xyl-t mutant. Plant Biotechnol J 5:389-401

Weng J-K, Chapple C (2010) The origin and evolution of lignin biosynthesis. New Phytol 187:273-285

Wolf L, Rizzini L, Stracke R, Ulm R, Rensing SA (2010) The molecular and physiological responses of Physcomitrella patens to ultravioletB radiation. Plant Physiol 153:1123-1134

Wood AJ, Oliver MJ (1999) Translational control in plant stress: the formation of messenger ribonucleoprotein particles (mRNPs) in response to desiccation of Tortula ruralis gametophytes. Plant J 18:359-370

Wu S-Z, Bezanilla M (2014) Myosin VIII associates with microtubule ends and together with actin plays a role in guiding plant cell division. eLife 3:e03498. doi:10.7554/eLife.03498

Xu L, Carrie C, Law SR, Murcha MW, Whelan J (2013) Acquisition, conservation, and loss of dual-targeted proteins in land plants. Plant Physiol 161:644-662

Xu B, Ohtani M, Yamaguchi M, Toyooka K, Wakazaki M, Sato M, Kubo M, Nakano Y, Sano R, Hiwatashi Y et al (2014) Contribution of
NAC transcription factors to plant adaptation to land. Science 343: $1505-1508$

Yamaguchi M, Mitsuda N, Ohtani M, Ohme-Takagi M, Kato K, Demura T (2011) VASCULAR-RELATED NAC-DOMAIN 7 directly regulates the expression of a broad range of genes for xylem vessel formation. Plant J 66:579-590

Yasumura Y, Moylan EC, Langdale JA (2005) A conserved transcription factor mediates nuclear control of organelle biogenesis in anciently diverged land plants. Plant Cell Online 17:1894-1907

Yasumura Y, Pierik R, Fricker MD, Voesenek LACJ, Harberd NP (2012) Studies of Physcomitrella patens reveal that ethylene-mediated submergence responses arose relatively early in land-plant evolution. Plant J 72:947-959

Zank TK, Zähringer U, Beckmann C, Pohnert G, Boland W, Holtorf H, Reski R, Lerchl J, Heinz E (2002) Cloning and functional characterisation of an enzyme involved in the elongation of $\Delta 6$ polyunsaturated fatty acids from the moss Physcomitrella patens. Plant J 31:255-268

Zhao J, Favero DS, Qiu J, Roalson EH, Neff MM (2014) Insights into the evolution and diversification of the AT-hook Motif Nuclear Localized gene family in land plants. BMC Plant Biol 14:266

Zimmer AD, Lang D, Buchta K, Rombauts S, Nishiyama T, Hasebe M, Van de Peer Y, Rensing SA, Reski R (2013) Reannotation and extended community resources for the genome of the non-seed plant Physcomitrella patens provide insights into the evolution of plant gene structures and functions. BMC Genomics 14:498 